\title{
Modeling of Flexible Polyurethane Foam Shrinkage for Bra Cup Moulding Process Control
}

\author{
Long $\mathrm{Wu}^{1}{ }^{1}$, Kit-Lun Yick ${ }^{2, *}$ (D), Sunpui $\mathrm{Ng}^{3}$ and Yue Sun ${ }^{2}$ \\ 1 Apparel \& Art Design College, Xi'an Polytechnic University, 19 Jinhua South Road, Xi'an 710048, China; \\ wulong7398@163.com \\ 2 The Institute of Textiles and Clothing, the Hong Kong Polytechnic University, Hung Hom, Kowloon, \\ Hong Kong, China; 16900113r@connect.polyu.hk \\ 3 Hong Kong Community College, the Hong Kong Polytechnic University, Hung Hom, Kowloon, Hong Kong, \\ China; ccspng@hkcc-polyu.edu.hk \\ * Correspondence: tcyick@polyu.edu.hk; Tel: +852-2766-6551
}

Received: 22 March 2018; Accepted: 21 April 2018; Published: 26 April 2018

\begin{abstract}
Nowadays, moulding technology has become a remarkable manufacturing process in the intimate apparel industry. Polyurethane (PU) foam sheets are used to mould three-dimensional (3D) seamless bra cups of various softness and shapes, which eliminate bulky seams and reduce production costs. However, it has been challenging to accurately and effectively control the moulding process and bra cup thickness. In this study, the theoretical mechanism of heat transfer and the thermal conductivity of PU foams are first examined. Experimental studies are carried out to investigate the changes in foam materials at various moulding conditions (viz., temperatures, and lengths of dwell time) in terms of surface morphology and thickness by using electron and optical microscopy. Based on the theoretical and experimental investigations of the thermal conductivity of the foam materials, empirical equations of shrinkage ratio and thermal conduction of foam materials were established. A regression model to predict flexible PU foam shrinkage during the bra cup moulding process was formulated by using the Levenberg-Marquardt method of nonlinear least squares algorithm and verified for accuracy. This study therefore provides an effective approach that optimizes control of the bra cup moulding process and assures the ultimate quality and thickness of moulded foam cups.
\end{abstract}

Keywords: polyurethane foams; bra cup moulding; process control; thermal conductivity; shrinkage

\section{Introduction}

Due to the growing importance of the intimate apparel market, there has been an ever-increasing interest in the bra cup moulding process for making seamless bras. In the bra cup moulding process, a pair of hot aluminum male and female moulds $\left(\sim 200^{\circ} \mathrm{C}\right)$ with conformed shapes is used to mould a piece of flat and flexible polyurethane (PU) foam sheet into a specified three-dimensional (3D) cup shape to fit the breast contour of the targeted customer. In common practice, the geometrical data of a specific 3D bra cup are acquired by a laser scanner. The data are further manipulated in a computer-aided design (CAD) system [1] and transferred to a computer numerical control (CNC) machine to mill two aluminum blocks which form a pair of male and female moulds. The specified 3D bra cup shape and volume are different to that of the cavity between the male and female moulds because the flexible PU foam sheet shrinks after moulding and cooling. The CAD operator must determine the foam shrinkage performance and incorporate this information when manipulating the scanned surface data. This is not an easy task because the thickness of the foam cup varies from the least amount of thickness at its edge to the most amount of thickness at its cup tip, i.e., the shrinkage ratio may vary along the cross-sectional geometry of the bra cup. As a result, the mould head design and 
bra-making process is highly complex, time-consuming, and error-prone due to the large variations in foam properties, cup styles and sizes, and geometric features of graduated padding. Moreover, the PU foam used for bra cup moulding is available in a diversity of hardness, thickness, and density as it is made from different chemical recipes that possess a wide range of physical, thermal, and mechanical properties which affect the degree of foam shrinkage after moulding [2]. To expedite control of the moulding process and to avoid costly trials and errors, previous studies [3,4] have identified the key material properties of PU foam materials that affect the cup shape after moulding, the level of breast support, as well as the tactile feel of the bra cup. The optimal temperature and dwell time for moulding bra cups are greatly affected by the compressive strain and the softening temperatures of PU foams measured by thermo-mechanical analyses. To evaluate the 3D geometrical shape of foam cups, several methods have been proposed to assess the 3D shape conformity and thickness of the moulded cups in objective ways [5,6]. More recently, a new parameterized-based remesh algorithm method has been introduced to measure the 3D shapes of the convex surface of scanned cup samples $[7,8]$. The shape conformity of the cup was successfully quantified in accordance with the corresponding mould head to determine the optimal moulding conditions, i.e., temperature and duration. Nevertheless, the results indicated that the shape of the foam cup can only adequately fit the aluminum mould head in the region of the cup tip even though the foam cup was moulded in optimal conditions. Substantial variations in cup shape and thickness were consistently observed, and the control of the bra cup moulding process is still far from reliable.

To enhance the quality and the process control of bra cup moulding, the mechanisms of heat transfer and the thermal conductivity of two kinds of PU foams are examined in this study. Dawson et al. [9] developed a model as functions of pressure and temperature using exponential equations to predict the relationship between the thermal conductivity and the specific volume behavior of amorphous polymers. A significant effect of temperature on the thermal conductivity of the material under the conditions of pressure in industrial polymer processing was found. Tseng et al. [10] proposed an analytical model to estimate the thermal conductivity of PU foam via heat transfer mechanisms. Erick et al. [11], and Fellah et al. [12], from a wave propagation aspect, provided different models of transmission of acoustic waves for porous materials with physical parameters. Placido et al. [13], and Wu [14] analyzed different foam insulation morphological structures and established a geometrical cell model which was applied to predict foam insulation properties. In their work, the geometrical structure of cellular foams played an important role in the study of thermal properties. Tao et al. [15] established a model for the thermal conductivity of open-cell, rigid PU foams from the ASTM C 518 method and validated the predicted values which were compared with experiment data. Wang and Pan [16] used a high-efficiency lattice Boltzmann method to numerically study the thermal conductivity of open-cell foam material.

The moulding process of bra cups transfers heat through the PU foam. The moulding temperature, dwell time, and mould gap determine the effects of the thermal conductivity of PU foam. In this work, an analytical model has been developed to address the shrinkage behavior of PU foams based on theoretical and experimental investigations of thermal conductivity. The model will not only provide a better understanding on the shrinkage mechanisms of foam materials, but will also help determine the appropriate moulding conditions for the bra cup moulding process and facilitate better quality control of the ultimate thickness of bra cups.

\section{Materials and Methods}

\subsection{Materials}

In this study, the materials used are flexible PU foams provided by a commercial bra cup manufacturer (Regina Miracle International Ltd., Shenzhen, China). The physical properties of the materials are summarized in Table 1 below. Both of the foam samples (I and II) have open-cell structures 
which have a relatively high water absorption and air permeability. The size of the sample sheets for the test is $20 \mathrm{~cm} \times 20 \mathrm{~cm} \times 1 \mathrm{~cm}$.

Table 1. Specifications and physical properties of the 2 polyurethane (PU) foam material samples.

\begin{tabular}{|c|c|c|c|c|c|c|}
\hline Style & $\begin{array}{l}\text { Density } \\
\left(\mathrm{kg} / \mathrm{m}^{3}\right)\end{array}$ & $\begin{array}{l}\text { Cell count (cells } \\
\text { per } 25 \mathrm{~mm} \text { ) }\end{array}$ & $\begin{array}{l}\text { Tensile strength } \\
\text { at } 8 \% \text { strain }(\mathbf{k P a})\end{array}$ & $\begin{array}{c}\text { Compression } \\
\text { stress at } 40 \% \\
\text { strain }(\mathrm{kPa})\end{array}$ & $\begin{array}{l}\text { Hardness } \\
\left({ }^{\circ} \mathrm{ShD}\right)\end{array}$ & Cell type \\
\hline $\begin{array}{c}\text { Test } \\
\text { standard }\end{array}$ & ISO845-1988 & AS2282.5-1999 & ISO1798-1983 & ISO3386/1-1986 & $\begin{array}{c}\text { ASTM } \\
\text { D2240-05 }\end{array}$ & \\
\hline Foam I & 45.07 & 44.30 & 4.80 & 4.27 & 43.98 & open \\
\hline Foam II & 28.23 & 46.20 & 2.80 & 2.16 & 21.96 & open \\
\hline
\end{tabular}

\subsection{Microscopy Analysis}

Due to the importance of the geometric structure of cellular foams as mentioned above, scanning electron microscopy (SEM) with a JEOL JSM-6490 (Tokyo, Japan) microscope was used in the investigation of surface morphology. By examining the SEM images of different foam samples, the reticular or cellular structures can be observed [15]. In the simplest case of the reticular structure of the PU foam, cells are open and the bulk material entirely concentrates on the cell sides, shaping the "struts". The interstitial gas is the same as the external environment gas, which is typically air. The images observed from SEM were used to determine the pore structure of the foams, including cell shape, cell diameter, cell area, etc.

\subsection{Moulding of PU Foam Specimens}

A contour moulding machine, New Pads moulding machine type DM-021HP4-2PR (NPI Co., Taiwan, China), which is commonly used in the industry, was employed to mould the PU foam sheets at different temperatures and durations. In this study, two aluminum top and bottom slabs are installed instead of two mould heads, and foam sheets that are $10 \mathrm{~mm}$ in thickness are compressed between hot and parallel slabs at four different distances apart, i.e., 1, 3, 5 and $7 \mathrm{~mm}$. Four pairs of standard rectangular bars were milled in the mentioned thicknesses and placed between the slabs to control the compression strain of the foam specimen during the moulding process. A PU foam sheet was placed on top of the bottom slab while the top slab was vertically brought down by compressed air and automatically lifted up after a duration of pre-set moulding time. Both slabs were heated to a predetermined temperature under the control of thermostats. The experimental setup of the moulding machine is shown in Figure 1. The ultimate thickness of the foam sheet after moulding is affected by the compression strain, the thermal and mechanical properties of the foam, and the moulding conditions. Specimens were allowed to cool down at room temperature for $24 \mathrm{~h}$ before the sheet thickness was measured [17]. The foam sheet specimens were moulded in temperatures which ranged from 180 to $210{ }^{\circ} \mathrm{C}$ in intervals of $10{ }^{\circ} \mathrm{C}$. The dwell time of the moulding process ranged from 60 to $180 \mathrm{~s}$ at $30 \mathrm{~s}$ intervals which were controlled by the moulding machine timer (NPI Co., Taiwan, China).
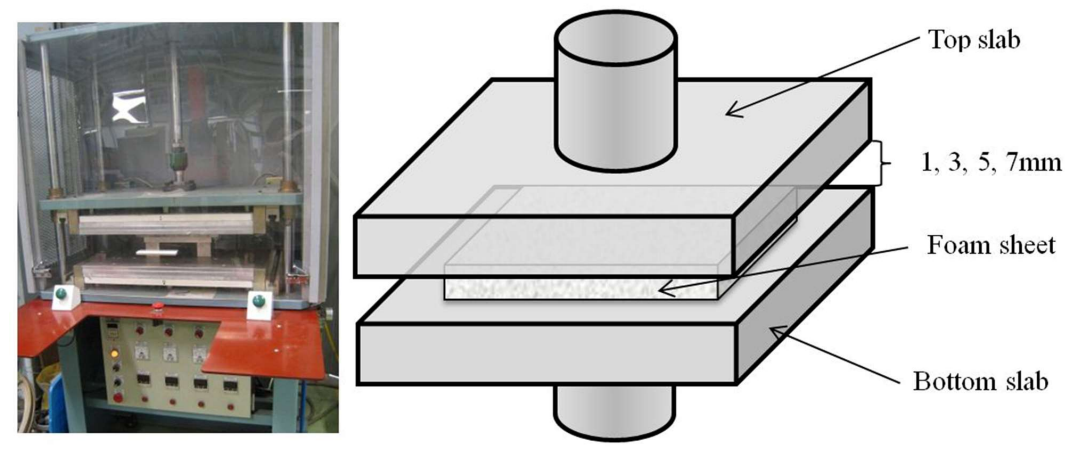

Figure 1. The experimental setup of the moulding machine. 


\subsection{Heat Transfer Mechanisms}

Polymers typically have low thermal conductivities, and consequently, the effects of the thermal conductivity of amorphous polymers are key to modeling under steady-state conditions [18]. The thermal conductivity controls the rate of heat transfer within the polymer and is relative to material composition, density, porosity, temperature, etc. [19]. During a high temperature manufacturing process, such as moulding, the polymer is first deformed and heated in a short period of time (e.g., $2 \mathrm{~min}$ ), and then it is fully relaxed and cooled afterwards. The final size and shape are highly dependent on the material's thermal conductivity, and it is therefore very important in determining the optimum processing conditions [20-22]. The thermal conductivity is the amount of heat transported per unit time through a unit area of a material with a unit length, per degree Kelvin of temperature difference between the two free ends of the material at a steady-state heat flow. For a given polymeric structure, the morphology, formulation, humidity, temperature, and pressure are the most important factors which affect the thermal conductivity [23].

Heat is transferred through the PU foam via four mechanisms: (1) gas conduction through the foam cells, $K_{\text {gas }}$; (2) solid conduction through the PU struts, $K_{\text {cond }}$; (3) radiation from the foam surface, $K_{\text {rad }}$; and (4) convection of gas inside the foam cells, $K_{c o n v}$. The total heat flow is a result of the interactions between the four modes below [10]:

$$
K_{e f f}=K_{g a s}+K_{c o n d}+K_{r a d}+K_{c o n v}
$$

The thermal conductivity due to conduction in the cell gas mixture has been calculated by using a modification of Wassiljewa's equation [24] as shown below:

$$
K_{g a s}=\sum_{i=1}^{n} \frac{y_{i} \cdot k_{i}}{\sum_{j=1}^{n} y_{j} \cdot A_{i j}}
$$

where $K_{g a s}$ is the thermal conductivity of the gas mixtures, $k_{i}$ is the thermal conductivity of the pure component $i$, and $y_{i}$ and $y_{j}$ are the molar fractions of the components $i$ and $j$, respectively. $A_{i j}$ is suggested by Mason and Saxena in the following form [10]:

$$
A_{i j}=\frac{\varepsilon\left[1+\left(\frac{k_{t r, i}}{k_{t r, j}}\right)^{\frac{1}{2}} \cdot\left(\frac{M_{i}}{M_{j}}\right)^{\frac{1}{4}}\right]^{2}}{\left[8\left(1+\frac{M_{i}}{M_{j}}\right)\right]^{\frac{1}{2}}}
$$

where $M_{i}$ and $M_{j}$ are the molecular weights of the pure components $i$ and $j(\mathrm{~g} / \mathrm{mol}), k_{t r, i}$ and $k_{t r, j}$ are the monatomic values of the thermal conductivity of the pure components $i$ and $j$, and $\varepsilon$ is an empirical constant.

Solid conduction in PU foams takes place through the cell walls and struts. The thermal conductivity due to the contribution of conduction through the polymer can be described by:

$$
K_{\text {cond }}=\frac{2}{3} K_{\rho}\left(1-\frac{f_{s}}{2}\right) \frac{\rho_{f}}{\rho_{s}}
$$

where $K_{\rho}$ is the thermal conductivity of the solid polymer $(\mathrm{W} / \mathrm{mK})$. The thermal conductivity of the solid PU polymer from crushed foam samples is reported to be $0.25 \mathrm{~W} / \mathrm{mK}$ [25] and the fraction of solids in the struts, $f_{s}$, has been reported to be 0.8 [26]. $\rho_{f}$ is the density of the foam $\left(\mathrm{kg} / \mathrm{m}^{3}\right)$, and $\rho_{s}$ is the density of the solid polymer $\left(\mathrm{kg} / \mathrm{m}^{3}\right)$.

The radiation model of heat transfer refers to the transport of energy by electromagnetic waves, and the attenuation of radiation takes place in the forms of reflection, absorption, and scattering. 
The radiation between the cell walls has been calculated by the Rossland equation [27] with the extinction coefficient of the cell wall material suggested by Glicksman [26].

$$
K_{r a d}=\frac{16 \sigma T^{3}}{3 K}, \text { where } K=\frac{4.1}{d \sqrt{\frac{f_{s} \rho_{f}}{\rho_{s}}}}
$$

where $\sigma$ represents the Stephan-Boltzman constant $\left(5.67 \times 10^{-8} \mathrm{~W} / \mathrm{m}^{2} \mathrm{~K}^{4}\right), T$ represents the Kelvin temperature $(\mathrm{K}), K$ represents the extinction coefficient $\left(\mathrm{m}^{-1}\right)$, and $d$ represents the cell diameter (m) [16].

The remaining mode of heat transfer is natural convection within the pores. It is negligible since the pore size is so small $(<0.5 \mathrm{~mm})$ that the Rayleigh number is much less than the critical value $(\sim 1000)$ for the onset of convection $[10,28]$.

\subsection{Thickness Measurement}

In industrial practice, the thickness of a moulded bra cup is measured from its cross-section which is obtained by cutting the cup through its peak. This destroys the cup sample and involves handling errors [29]. In this study, a noncontact optical microscopy measuring instrument (LEICA M165C, Wetzlar, Germany) is adopted to scan the foam sheet and confirm its thickness before and after moulding $[30,31]$. The thickness of the foam samples taken at three points which are evenly distributed in the transverse direction was accurately identified, and there were three replicates for each group.

\subsection{Shrinkage Ratio}

Both industrial and experimental studies have revealed that different moulding temperatures and dwell times could result in thermal shrinkage, in which the foam cup thickness is generally smaller than the gap distance between the male and female mould heads. In this study, the shrinkage ratio of the foam sheets is described below [32].

$$
S R=\frac{T_{t}-T_{0}}{T_{\text {Original }}-T_{0}}+0.1
$$

where $S R$ is the shrinkage ratio; $T_{t}$ is the postmoulding thickness of different dwell times $(\mathrm{mm}) ; T_{0}$ is the thickness of the longest dwell time (mm); and $T_{\text {Original }}$ is the pre-moulding foam thickness $(\mathrm{mm})$.

\section{Results and Discussion}

\subsection{Scanning Electron Microscopy (SEM)}

The cellular structures of Foam I under different moulding conditions are presented in Figure 2. A microscopic view of the pore structure of Foam I is shown in Figure 2a. The solid matrix is made of struts, and the cell shape resembles a pentagonal dodecahedron [13]. Moreover, strut thickness is always much smaller than cell diameter. The cells are randomly oriented, and they are mostly homogeneous in size and shape [30]. The pore size varies from approximately 0.4 to $0.8 \mathrm{~mm}$. The mean value of the cell diameter which characterizes the cellular structure is $0.543 \mathrm{~mm}$. Figure $2 b, c$ show images of the same foam that has been moulded under different conditions. It is clear that the cell struts are deformed after compression at a moulding temperature of $463 \mathrm{~K}$ and dwell time of $90 \mathrm{~s}$, while the pore walls and struts are further distorted under the moulding condition of $473 \mathrm{~K}$ and $120 \mathrm{~s}$. 


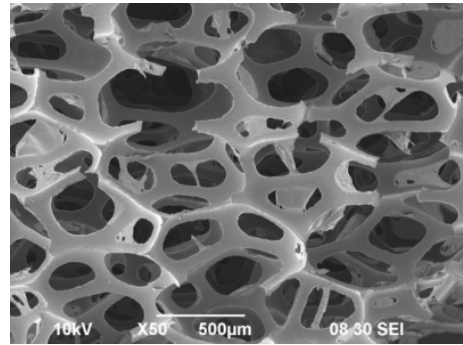

(a) control

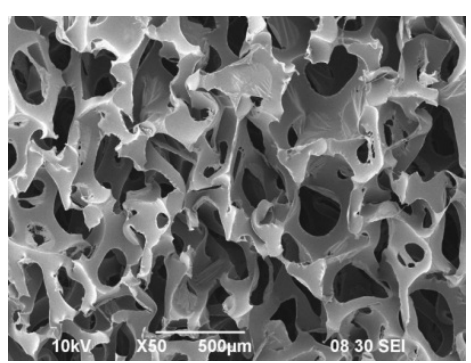

(b) moulded at $463 \mathrm{~K}$ and $90 \mathrm{~s}$

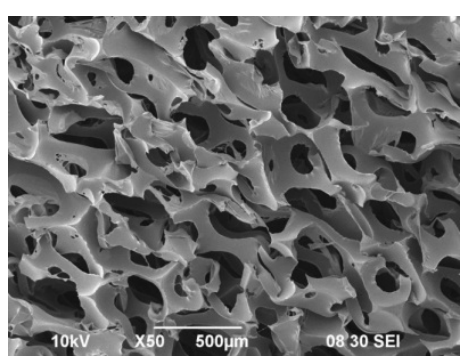

(c) moulded at $473 \mathrm{~K}$ and $120 \mathrm{~s}$

Figure 2. Cellular structure of PU foam (Foam I) under different moulding conditions.

\subsection{Shrinkage Ratio and Dwell Time}

The changes in foam shrinkage ratios with different lengths of dwell time are presented in Figure 3. As shown, the shrinkage ratio appears to exponentially decline with the dwell time except at the state where it fails to reach the threshold for forming foam. At lower temperatures and shorter dwell times, the shrinkage ratio takes on a greater value and vice versa. Through a nonlinear regression model, which is an exponential equation, the shrinkage ratio can be predicted by dwell time as well as two empirical constants, $A$ and $B$, with reasonable accuracy.

$$
S R=A e^{-B t}
$$

where $S R$ means shrinkage ratio, and $t$ means dwell time (s).

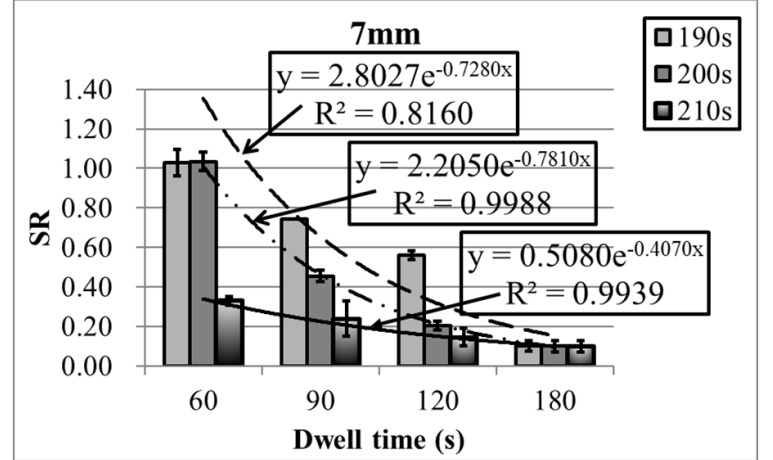

$S R$ vs. dwell time for gap of $7 \mathrm{~mm}$ in Foam I

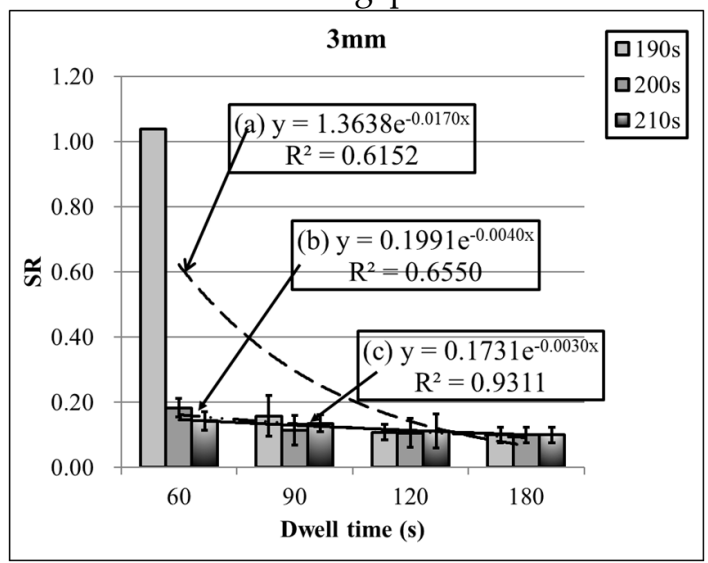

$S R$ vs. dwell time for gap of $3 \mathrm{~mm}$ in Foam I

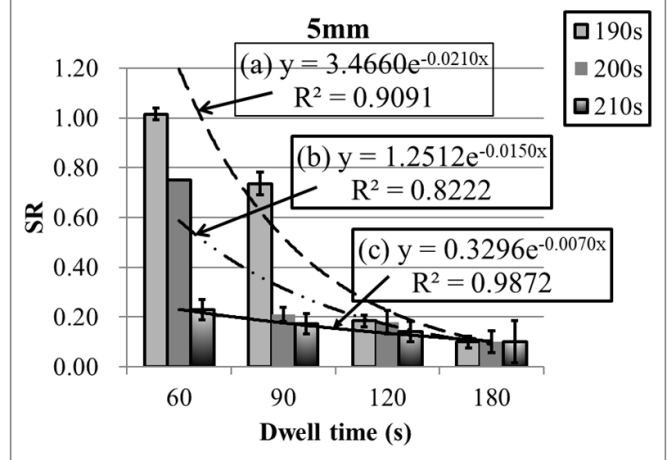

$S R$ vs. dwell time for gap of $5 \mathrm{~mm}$ in Foam I

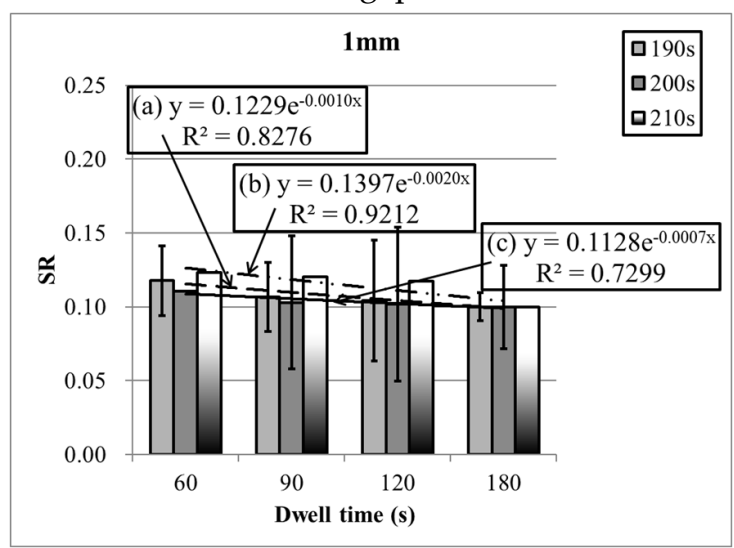

$S R$ vs. dwell time for gap of $1 \mathrm{~mm}$ in Foam I

Figure 3. Regression curves of dwell time vs. moulding temperature with different gaps. 
With reference to the Arrhenius equation [33], pre-exponential factor $A$ and empirical constant $B$ control the variation trend of the shrinkage ratio. As shown in Figure 3, the PU foam has a higher shrinkage ratio at a relatively low temperature. With the extension of dwell time, the shrinkage ratio rapidly drops. If the dwell time continues to be further extended, the decline rate of the shrinkage ratio will be reduced and a balance is obtained.

\subsection{Thermal Conduction Analysis}

Since the ultimate thickness of the bra cup will also be affected by the moulding temperature, the gap distance between the male and female mould heads and the foam material properties during the thermal conduction process for bra cup moulding is investigated. It is necessary to find the relationship among the three influential factors of conductive and radiative properties with the two coefficients of the exponential equation.

$$
\begin{aligned}
& A=f(\text { Gap }, \text { Temp }, \text { Foam properties }) \\
& B=f(\text { Gap, Temp, Foam properties })
\end{aligned}
$$

As previously shown in the equations, the dependence of radiative and conductive properties are relevant to the moulding temperature, the dwell time, and the geometrical parameters which characterize the internal foam structure, such as the mean wall thickness, the mean strut, and the cell diameters [13]. As the density of foam varies with the gap between the two slabs, the equation can be deduced as shown below.

$$
K_{\text {cond }}=\frac{2}{3} K_{\rho}\left(1-\frac{f_{s}}{2}\right) \frac{\rho_{f}}{\rho_{s}}=\frac{2}{3} \cdot 0.25 \cdot\left(1-\frac{0.8}{2}\right) \cdot \frac{1}{1100} \cdot \frac{T_{0} \cdot \rho_{0}}{T_{h}}=f\left(T_{h}\right)
$$

Foam I: $K_{\text {cond }}=\frac{0.001}{T_{h}}$ and Foam II: $K_{\text {cond }}=\frac{0.00068}{T_{h}}$ where $T_{h}$ means the gap between the two slabs (m).

$$
K_{\text {rad }}=\frac{16 \sigma T^{3}}{3 \frac{4.1}{d \sqrt{\frac{f_{s} \rho_{f}}{\rho_{s}}}}}=\frac{16 \cdot 5.67 \cdot 10^{-8} \cdot T^{3} \cdot T_{h} \cdot d_{0} \cdot \sqrt{1100 \cdot T_{h}}}{3 \cdot 4.1 \cdot 0.01 \cdot \sqrt{0.8 \cdot \rho_{0} \cdot 0.01}}=f\left(T, T_{h}, d_{0}\right)
$$

where $\rho_{f}=\frac{0.01 \cdot \rho_{0}}{T_{h}}$ and $d=\frac{T_{h}}{T_{h 0}} \cdot d_{0}$.

As the cells are open and the interstitial gas is the same as the external environment gas as previously described, then $K_{g a s}$ could be derived from Equation (2) below:

$$
K_{\text {gas }}=0.001 \cdot(0.0793 \cdot T-6.99)=f(T)
$$

where $K_{g a s}$ is the thermal conductivity due to the contribution of conduction through the gas in the cell and $T$ is the temperature in $\mathrm{K}$. Table 2 shows the thermal conduction values under different conditions of Foams I and II.

As evidenced from Table 2, the conduction in the cell gas mixture stands for the main part of the thermal conductivity of foam. About $65-80 \%$ of the insulation capacity of a foam is due to the cell gas mixture, while cell size and density contribute to the remaining portion [34]. Due to a smaller variation range of moulding temperatures, the heat transfer of $K_{g a s}$ essentially remains unchanged compared to the other two factors, which are solid conduction and thermal radiation. Therefore, in regression models, only $K_{\text {cond }}$ and $K_{\text {rad }}$ are used to predict the effects of solid conduction and radiation on the two coefficients of an exponential equation, and nonlinear regression models, which use the Gauss-Newton algorithm, are adopted for fitting. 
Table 2. Radiative and conductive properties and the two coefficients in the exponential equation.

\begin{tabular}{cccccccccc}
\hline Foam type & Gap (m) & Temp. (K) & $\boldsymbol{A}$ & $\boldsymbol{B}$ & $\boldsymbol{R}^{\mathbf{2}}$ & $\begin{array}{c}\boldsymbol{K}_{\text {cond }} \\
\mathbf{( W / m K )}\end{array}$ & $\begin{array}{c}\boldsymbol{K}_{\text {gas }} \\
\text { (W/mK) }\end{array}$ & $\begin{array}{c}\boldsymbol{K}_{\text {rad }} \\
\text { (W/mK) }\end{array}$ & $\begin{array}{c}\boldsymbol{K}_{\text {eff }} \\
\text { (W/mK) }\end{array}$ \\
\hline I & 0.007 & 463 & 4.136 & 0.020 & 0.935 & 0.006 & 0.030 & 0.013 & 0.048 \\
I & 0.007 & 473 & 2.718 & 0.019 & 0.952 & 0.006 & 0.031 & 0.014 & 0.050 \\
I & 0.007 & 483 & 0.570 & 0.010 & 0.958 & 0.006 & 0.031 & 0.015 & 0.052 \\
I & 0.005 & 463 & 3.466 & 0.021 & 0.909 & 0.008 & 0.030 & 0.008 & 0.046 \\
I & 0.005 & 473 & 1.251 & 0.015 & 0.822 & 0.008 & 0.031 & 0.008 & 0.047 \\
I & 0.005 & 483 & 0.330 & 0.007 & 0.987 & 0.008 & 0.031 & 0.009 & 0.048 \\
I & 0.003 & 463 & 1.364 & 0.017 & 0.615 & 0.014 & 0.030 & 0.004 & 0.047 \\
I & 0.003 & 473 & 0.199 & 0.004 & 0.655 & 0.014 & 0.031 & 0.004 & 0.048 \\
I & 0.003 & 483 & 0.173 & 0.003 & 0.931 & 0.014 & 0.031 & 0.004 & 0.049 \\
I & 0.001 & 463 & 0.123 & 0.001 & 0.828 & 0.041 & 0.030 & 0.001 & 0.071 \\
I & 0.001 & 473 & 0.113 & 0.001 & 0.730 & 0.041 & 0.031 & 0.001 & 0.072 \\
I & 0.001 & 483 & 0.140 & 0.002 & 0.921 & 0.041 & 0.031 & 0.001 & 0.073 \\
II & 0.007 & 463 & 2.466 & 0.017 & 0.918 & 0.004 & 0.030 & 0.016 & 0.049 \\
II & 0.007 & 473 & 1.029 & 0.013 & 0.901 & 0.004 & 0.031 & 0.017 & 0.051 \\
II & 0.007 & 483 & 0.819 & 0.012 & 0.964 & 0.004 & 0.031 & 0.018 & 0.053 \\
II & 0.005 & 463 & 1.965 & 0.018 & 0.874 & 0.005 & 0.030 & 0.009 & 0.044 \\
II & 0.005 & 473 & 0.736 & 0.012 & 0.908 & 0.005 & 0.031 & 0.010 & 0.046 \\
II & 0.005 & 483 & 0.393 & 0.008 & 0.881 & 0.005 & 0.031 & 0.011 & 0.047 \\
II & 0.003 & 463 & 0.594 & 0.011 & 0.638 & 0.009 & 0.030 & 0.004 & 0.043 \\
II & 0.003 & 473 & 0.203 & 0.004 & 0.789 & 0.009 & 0.031 & 0.005 & 0.044 \\
II & 0.003 & 483 & 0.149 & 0.003 & 0.702 & 0.009 & 0.031 & 0.005 & 0.045 \\
II & 0.001 & 463 & 0.146 & 0.002 & 0.620 & 0.026 & 0.030 & 0.001 & 0.056 \\
II & 0.001 & 473 & 0.112 & 0.001 & 0.857 & 0.026 & 0.031 & 0.001 & 0.057 \\
II & 0.001 & 483 & 0.134 & 0.002 & 0.869 & 0.026 & 0.031 & 0.001 & 0.058 \\
\hline
\end{tabular}

\subsection{Regression Model}

The relationships between the coefficients of the exponential equation and the two heat transfer modes, which are $K_{\text {cond }}$ and $K_{\text {rad }}$, are examined. A software of Table Curve 3D (SYSTAT, San Jose, CA, USA) by nonlinear regression was used. The fitting procedure was based on the Gauss-elimination algorithm by minimizing the sum of the squares of errors between the data and model regressions. A nonlinear regression was then undertaken, and coefficients can be derived as shown in the equation below:

$$
\begin{gathered}
A=a_{1}+\frac{b_{1}}{\sqrt{K_{\text {cond }}^{3}}}+c_{1} \cdot K_{\text {rad }} \\
B=a_{2}+\frac{b_{2}}{\sqrt{K_{\text {cond }}}}+\frac{c_{2}}{\ln K_{\text {rad }}}
\end{gathered}
$$

where $A$ and $B$ are calculated as the two coefficients of the exponential Equation (6); $K_{\text {cond }}(\mathrm{W} / \mathrm{mK})$ and $K_{\text {rad }}(\mathrm{W} / \mathrm{mK})$ are the solid and radiative conductivities, respectively; and $a_{1}, a_{2}, b_{1}, b_{2}, c_{1}$, and $c_{2}$ are the constants. Through the equations, coefficients $A$ and $B$ could be predicted according to effective thermal conductivity due to solid conduction and radiation. An example of the regression model for Foam I is formulated as shown below:

$$
\begin{gathered}
A=-0.0256+\frac{0.0153}{\sqrt{K_{\text {cond }}^{3}}}-2299.6913 K_{\text {rad }} \\
B=0.1506+\frac{0.0246}{\sqrt{K_{\text {cond }}}}+\frac{1.9564}{\ln K_{\text {rad }}}
\end{gathered}
$$

The determination coefficients $\left(R^{2}\right)$ of regression Equations (14) and (15) obtained from Foam I are higher than 0.89 with a significance level $\leq 0.001$. 
Another regression model for Foam II is formulated as shown below:

$$
\begin{gathered}
A=-0.0093+\frac{0.0036}{\sqrt{K_{\text {cond }}^{3}}}-894.4124 \cdot K_{\text {rad }} \\
B=0.0765+\frac{0.0115}{\sqrt{K_{\text {cond }}}}+\frac{1.0360}{\ln K_{\text {rad }}}
\end{gathered}
$$

In the same way, the determination coefficients $\left(R^{2}\right)$ of regression Equations (16) and (17) obtained from Foam II are higher than 0.83 , with a significance level $\leq 0.001$.

In accordance with the relationship between the shrinkage ratio and the coefficients of the exponential equation in Equation (6), and combining the dwell time, the whole shrinkage ratio equation is built as shown below:

$$
S R=\left(A_{1}-\frac{A_{2}}{\sqrt{K_{\text {cond }}^{3}}}+A_{3} \cdot K_{\text {rad }}\right) \cdot e^{\left(A_{4}+\frac{A_{5}}{\sqrt{K_{\text {cond }}}}+\frac{A_{6}}{\ln K_{\text {rad }}}\right)}+A_{7}
$$

From Equation (18) above, there are a total of seven coefficients which determine the entire equation. In regards to a particular kind of foam, at least seven experimental runs need to be carried out to predict the shrinkage ratio. Seven representative moulding conditions were selected randomly, and afterwards, the shrinkage ratios, $K_{\text {cond }}$ and $K_{\text {rad }}$, can be calculated in terms of moulding parameters. Finally, each coefficient value could be determined by using the Levenberg-Marquardt method of nonlinear least squares optimized algorithm. In this way, the shrinkage ratio equations of Foams I and II are shown as follows:

$$
\begin{gathered}
S R=\left(6.6247-\frac{0.0525}{\sqrt{K_{\text {cond }}^{3}}}+8772.8232 K_{\text {rad }}\right) \cdot e^{\left(0.5165+\frac{0.0938}{\sqrt{K_{\text {cond }}}}+\frac{7.6488}{\ln K_{\text {rad }}}\right)}+0.0969 \\
S R=\left(18.4608-\frac{0.0128}{\sqrt{K_{\text {cond }}^{3}}}+2767.0344 K_{\text {rad }}\right) \cdot e^{\left(0.2234+\frac{0.0547}{\left.\sqrt{K_{\text {cond }}}+\frac{4.8058}{\ln K_{\text {rad }}}\right)}+0.1241\right.}
\end{gathered}
$$

Both equations pass the significance test with decision coefficients by 0.87 and 0.93 , respectively.

\subsection{Verification of the Shrinkage Ratio Model}

The 16 random verification runs were conducted by an experimental process. There were also three replicates of the thickness measurements for each group. In Table 3, the two rightmost columns are $S R_{\text {exp }}$ and $S R_{\text {pred }}$, which indicate the experimental and predictive results of the shrinkage ratio, respectively. The remaining left columns are run number, foam type, and test conditions, respectively. The detailed moulding conditions include temperature, dwell time, and gap. $K_{c o n d}$ and $K_{\text {rad }}$ can be further calculated from Equations (9) and (10).

The residual analysis of the normal probability plot indicates that the shrinkage ratio model is well available for both the fitting and the forecasting (see Figure 4). It provides a reliable and effective prediction of the post-moulding thickness of foam cups.

A comparison between the predictions and the measured data of the shrinkage ratio results from the experiments is shown in Figure 5. There is at least a 93.1\% agreement in 16 different experimental conditions for both foam types between the experimental and simulation curves in these experiments. This might indicate that a higher order regression model for the control factors may not be required. 
Table 3. The 16 random verification runs of each foam.

\begin{tabular}{|c|c|c|c|c|c|c|c|c|}
\hline Run No. & Type & $\begin{array}{c}K_{\text {cond }} \\
\text { (W/mK) }\end{array}$ & $\begin{array}{c}K_{\text {rad }} \\
\text { (W/mK) }\end{array}$ & Time (s) & Gap (m) & Temp. (K) & $S R_{\exp }$ & $S R_{\text {pred }}$ \\
\hline 1 & \multirow{16}{*}{ Foam I } & 0.00585 & 0.01288 & 90 & 0.007 & 463 & 0.7415 & 0.7117 \\
\hline 2 & & 0.00585 & 0.01373 & 60 & 0.007 & 473 & 1.0343 & 0.9535 \\
\hline 3 & & 0.00585 & 0.01373 & 120 & 0.007 & 473 & 0.2031 & 0.1728 \\
\hline 4 & & 0.00585 & 0.01462 & 90 & 0.007 & 483 & 0.2383 & 0.1393 \\
\hline 5 & & 0.00819 & 0.00778 & 90 & 0.005 & 463 & 0.7363 & 0.6633 \\
\hline 6 & & 0.00819 & 0.00829 & 60 & 0.005 & 473 & 0.7502 & 0.7553 \\
\hline 7 & & 0.00819 & 0.00829 & 120 & 0.005 & 473 & 0.1794 & 0.1481 \\
\hline 8 & & 0.00819 & 0.00883 & 90 & 0.005 & 483 & 0.1737 & 0.1390 \\
\hline 9 & & 0.01366 & 0.00361 & 90 & 0.003 & 463 & 0.1579 & 0.2355 \\
\hline 10 & & 0.01366 & 0.00385 & 60 & 0.003 & 473 & 0.1829 & 0.3508 \\
\hline 11 & & 0.01366 & 0.00385 & 120 & 0.003 & 473 & 0.1057 & 0.1055 \\
\hline 12 & & 0.01366 & 0.00410 & 90 & 0.003 & 483 & 0.1356 & 0.1115 \\
\hline 13 & & 0.04097 & 0.00070 & 60 & 0.001 & 463 & 0.1178 & 0.1783 \\
\hline 14 & & 0.04097 & 0.00070 & 120 & 0.001 & 463 & 0.1041 & 0.0979 \\
\hline 15 & & 0.04097 & 0.00074 & 90 & 0.001 & 473 & 0.1029 & 0.1015 \\
\hline 16 & & 0.04097 & 0.00079 & 60 & 0.001 & 483 & 0.1230 & 0.1282 \\
\hline 1 & \multirow{16}{*}{ Foam II } & 0.00367 & 0.01550 & 90 & 0.007 & 463 & 0.3707 & 0.4821 \\
\hline 2 & & 0.00367 & 0.01653 & 60 & 0.007 & 473 & 0.5457 & 0.5872 \\
\hline 3 & & 0.00367 & 0.01653 & 120 & 0.007 & 473 & 0.2628 & 0.1554 \\
\hline 4 & & 0.00367 & 0.01760 & 90 & 0.007 & 483 & 0.2657 & 0.1577 \\
\hline 5 & & 0.00513 & 0.00936 & 90 & 0.005 & 463 & 0.3166 & 0.3541 \\
\hline 6 & & 0.00513 & 0.00998 & 60 & 0.005 & 473 & 0.4396 & 0.5227 \\
\hline 7 & & 0.00513 & 0.00998 & 120 & 0.005 & 473 & 0.1456 & 0.1381 \\
\hline 8 & & 0.00513 & 0.01062 & 90 & 0.005 & 483 & 0.1585 & 0.1480 \\
\hline 9 & & 0.00855 & 0.00435 & 90 & 0.003 & 463 & 0.1358 & 0.1537 \\
\hline 10 & & 0.00855 & 0.00464 & 60 & 0.003 & 473 & 0.1767 & 0.2539 \\
\hline 11 & & 0.00855 & 0.00464 & 120 & 0.003 & 473 & 0.1082 & 0.1252 \\
\hline 12 & & 0.00855 & 0.00494 & 90 & 0.003 & 483 & 0.1123 & 0.1290 \\
\hline 13 & & 0.02566 & 0.00084 & 60 & 0.001 & 463 & 0.1407 & 0.1434 \\
\hline 14 & & 0.02566 & 0.00084 & 120 & 0.001 & 463 & 0.1022 & 0.1241 \\
\hline 15 & & 0.02566 & 0.00089 & 90 & 0.001 & 473 & 0.1055 & 0.1245 \\
\hline 16 & & 0.02566 & 0.00095 & 60 & 0.001 & 483 & 0.1186 & 0.1337 \\
\hline
\end{tabular}
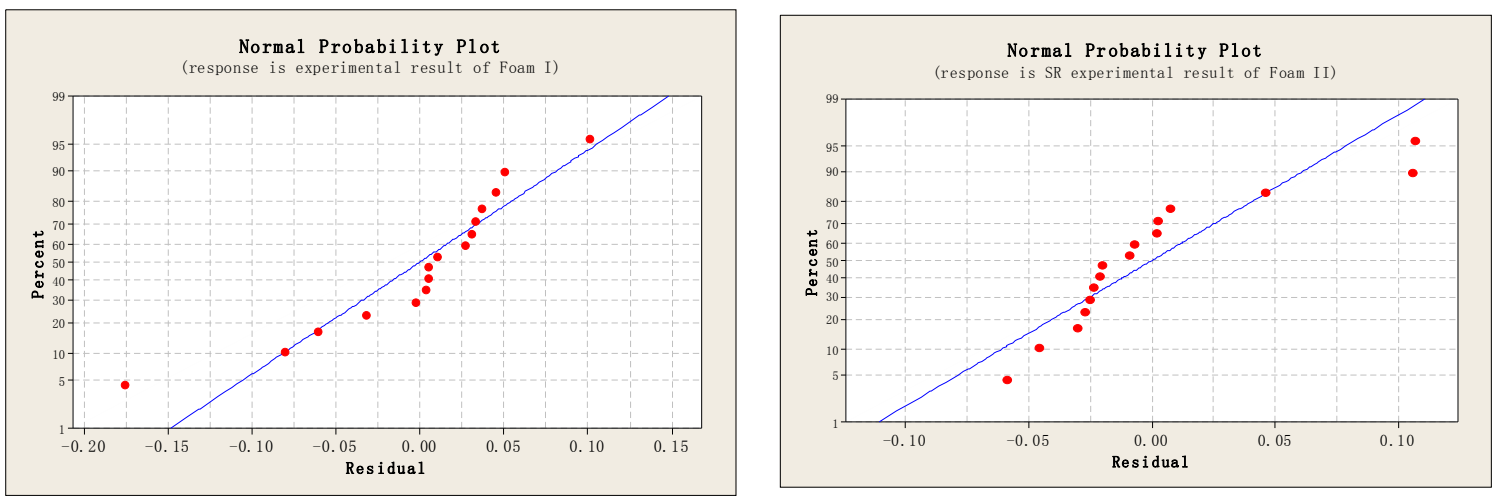

Figure 4. Residual analysis of normal probability plots for shrinkage ratio of Foams I and II. 

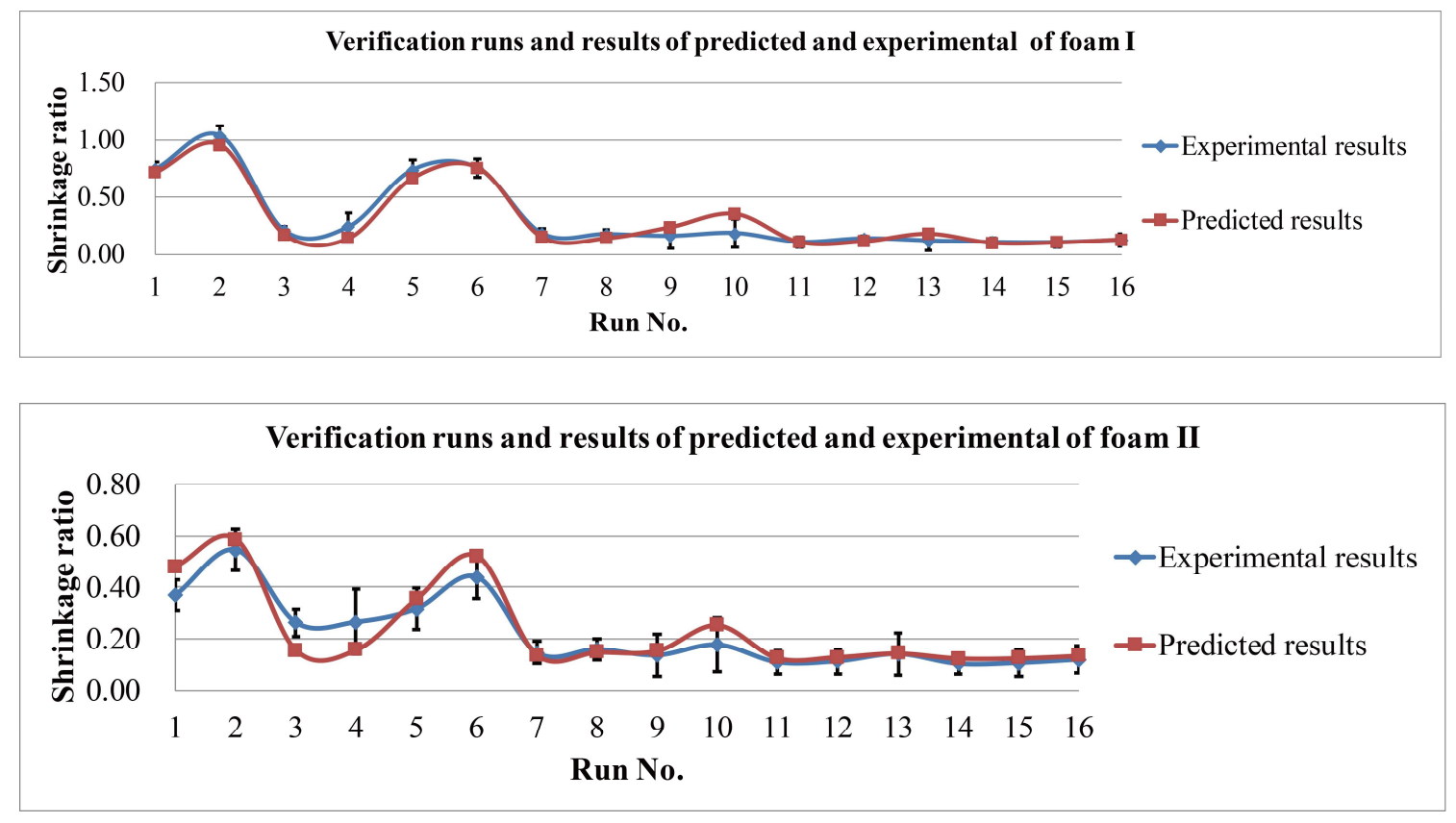

Figure 5. Simulation and experimental results of Foams I and II.

\section{Conclusions}

In this study, the heat transfer mechanisms in PU foam are discussed, and heat transfer modes are used to build an analytical model to estimate the shrinkage ratio. As the surfaces of bra cup mould heads are not parallel, the distance between each gap in the male and female mould heads is not the same. The post-moulding thicknesses of bra cups in different positions can be derived from corresponding gap distances between mould heads based on the shrinkage ratio equation in terms of different moulding conditions. This study has characterized heat transfer mechanisms of various material types in the moulding behavior, and it has also identified the relationships between foam properties, moulding conditions, and the shrinkage ratio of foams. Through the Levenberg-Marquardt method of nonlinear least squares algorithm, a prediction model is regressed to predict the shrinkage in the thickness of flexible PU foam after the moulding process. The application of the model can shorten the product development cycle, reduce design costs, and avoid duplication errors. Engineers and designers in the moulding design and processing sectors would benefit through an improved accuracy of processing predictions by the incorporation and use of moulding temperature, dwell time, gap between the two slabs, and foam material properties, as well as thermal conductivity data.

Author Contributions: Sunpui $\mathrm{Ng}$ and Kit-Lun Yick conceived and designed the experiments; Long $\mathrm{Wu}$ performed the experiments; Kit-Lun Yick and Sunpui $\mathrm{Ng}$ analyzed the data; Long Wu contributed reagents/materials/analysis tools; Long Wu and Yue Sun wrote the paper.

Acknowledgments: The authors would like to thank the Research Grant Council for funding this research through project accounts PolyU 152375/16E and PolyU 152205/14E. The authors give thanks to the anonymous reviewers for their valuable comments and suggestions.

Conflicts of Interest: The authors declare no conflict of interest.

\section{References}

1. Vidal, F.; González, R.; Fontán, M.; Rico, P.; Piñeiro, D. Development of a flexible robotic cell for laser cutting of 3D foam and preformed fabric. Robot. Smart Manuf. 2013, 371, 91-100.

2. Elkholy, G.A.; Hafny, S. Study of Fabrics Properties for Intimate Apparel Application. Int. J. Sci. Eng. Investig. 2017, 62, 139-144. 
3. Deng, R.; Davis, P.; Bajag, A.K. Flexible polyurethane foam modeling and viscoelastic parameters identification for automotive seating applications. J. Sound Vib. 2003, 262, 391-417. [CrossRef]

4. Yu, W.M. The Effect of Polyurethane Foam Properties and Moulding Conditions on the Shape Characteristics of Brassiere Cups. Ph.D. Thesis, The University of Leeds, Leeds, UK, 1996.

5. Yick, K.L.; Yu, W.; Ng, S.P.; Yip, J.; Wu, L. Foam moulding performance and conditions for seamless bra cup. In Proceedings of the 86th Textile Institute World Conference, Hong Kong, China, 18-21 November 2008.

6. Yip, J.; $\mathrm{Ng}$, S.P. Study of three-dimensional spacer fabrics: Molding properties for intimate apparel application. J. Mater. Process. Technol. 2009, 209, 58-62. [CrossRef]

7. Yick, K.L.; Ng, S.P.; Zhou, X.J.; Yu, W.; Chan, D. Wire frame representation of 3D moulded bra cup and its application to example-based design. Fibers Polym. 2008, 9, 653-658. [CrossRef]

8. Yick, K.L.; Wu, L.; Yip, J.; Ng, S.P.; Yu, W. Study of thermal-mechanical properties of polyurethane foam and the three-dimensional shape of molded bra cups. J. Mater. Process. Technol. 2010, 210, 116-121. [CrossRef]

9. Dawson, A.; Rides, M.; Nottay, J. The effect of pressure on the thermal conductivity of polymer melts. Polym. Test. 2006, 26, 268-275. [CrossRef]

10. Tseng, C.J.; Yamaguchi, M.; Ohmori, T. Thermal conductivity of polyurethane foams from room temperature to 20 K. Cryogenics 1997, 37, 305-312. [CrossRef]

11. Ogam, E.; Fellah, Z.E.A.; Baki, P. The inverse problem of acoustic wave scattering by an air-saturated poroelastic cylinder. J. Acoust. Soc. Am. 2013, 133, 1443-1457. [CrossRef] [PubMed]

12. Fellah, Z.E.A.; Fellah, M.; Depollier, C.; Ogam, E.; Mitri, F.G. Wave Propagation in Porous Materials. In Computational and Experimental Studies of Acoustic Waves (Chapter 6); InTech: London, UK, 2018; pp. $99-119$.

13. Placido, E.; Arduini-Schuster, M.; Kuhn, J. Thermal properties predictive model for insulating foams. Infrared Phys. Technol. 2005, 46, 219-231. [CrossRef]

14. Wu, J.W.; Sung, W.F.; Chu, H.S. Thermal conductivity of polyurethane foams. Int. J. Heat Mass Transf. 1999, 42, 2211-2217. [CrossRef]

15. Tao, W.H.; Hsu, H.C.; Chang, C.C.; Hsu, C.L.; Lin, Y.S. Measurement and prediction of thermal conductivity of open cell rigid polyurethane foam. J. Cell Plast. 2001, 37, 310-332. [CrossRef]

16. Wang, M.; Pan, N. Modeling and prediction of the Effective Thermal Conductivity of Random Open-cell Porous Foams. Int. J. Heat Mass Transf. 2008, 51, 1325-1331. [CrossRef]

17. Yu, W.M.; Yeung, K.W.; Harlock, S.C.; Leaf, G.A.V. Predicting energy requirements for moulding flexible polyurethane foam sheets. Text. Res. J. 1998, 68, 289-295. [CrossRef]

18. Dawson, A.; Rides, M.; Allen, C.R.G.; Urquhart, J.M. Polymer-mould interface heat transfer coefficient measurements for polymer processing. Polym. Test. 2008, 27, 555-565. [CrossRef]

19. Nylund, C.; Meinander, K. The influence of heat transfer coefficient on cooling time in injection molding. Int. J. Heat Mass Transf. 2005, 41, 428-431. [CrossRef]

20. Rauwendaal, C. Important Polymer Properties. In Polymer Extrusion, 2nd ed.; Hanser Publisher: Munich, Germany, 1990; pp. 191-253.

21. Menges, G.; Mohren, P. The Heat Exchange System. In How to Make Injection Molds, 3rd ed.; Hanser Publishers: Munich, Germany, 2001; pp. 271-312.

22. Throne, J.L. Polyumeric materials. In Thermoforming; Hanser Publishers: Munich, Germany, 1987; pp. $39-57$.

23. Bicerano, J. Thermal conductivity and thermal diffusivity. In Prediction of Polymer Properties, 3rd ed.; Marcel Dekker Inc.: New York, NY, USA, 2002; pp. 503-512.

24. Wassiljewa, A. Wärmeleitung in gasgemischen. Phys. Z. 1904, 5, 737-742.

25. Hillyard, N.C.; Cunnigham, A. Heat transfer in foams. In Low Density Cellular Plastics; Chapman and Hall: London, UK, 1994; pp. 104-139.

26. Sinofsky, M. Property Measurement and Thermal Performance Predictiong of Foam Insulation. Master's Thesis, MIT, Cambridge, UK, 1984.

27. Chamkha, A.J.; Mujtaba, M.; Quadri, A.; Issa, C. Thermal radiation effects on MHD forced convection flow adjacent to a non-isothermal wedge in the presence of a heat source or sink. Int. J. Heat Mass Transf. 2003, 39, 305-312. [CrossRef]

28. Skochdopole, R.E. The thermal conductivity of foam plastics. Eng. Prog. 1961, 57, 55-59.

29. Yu, W.M.; Yeung, K.W.; Harlock, S.C.; Leaf, G.A.V. Mathematical measures of shape conformity. J. China Text I 1997, 14, 21-27. 
30. Rodriguez-Perez, M.A.; Alonso, O.; Souto, J.; Saja, J.A.D. Thermal conductivity of physically crosslinked closed cell polyolefin foams. Polym. Test. 1997, 16, 287-298. [CrossRef]

31. Chang, L.C.; Sain, M.; Kortschot, M. Effect of mixing conditions on the morphology and performance of fiber-reinforced polyurethane foam. J. Cell Plast. 2015, 51, 103-119. [CrossRef]

32. Chong, R. Moulding \& Lamination Technology Handbook for Lingerie Industry; HongKong Productivity Council: Hong Kong, China, 2009; pp. 83-84.

33. Bilbao, R.; Mastral, J.F.; Ceamanos, J.; Aldea, M.E. Kinetics of the thermal decomposition of polyurethane foams in nitrogen and air atmospheres. J. Anal. Appl. Pyrol. 1996, 37, 69-82. [CrossRef]

34. Jarfelt, U.; Ramnas, O. Thermal conductivity of polyurethane foam-Best performance. In Proceedings of the 10th International Symposium on District Heating and Cooling, Hanover, Germany, 3-5 September 2006.

(C) 2018 by the authors. Licensee MDPI, Basel, Switzerland. This article is an open access article distributed under the terms and conditions of the Creative Commons Attribution (CC BY) license (http:/ / creativecommons.org/licenses/by/4.0/). 